\title{
Cholesterol reducer and thrombolytic therapy in acute ischemic stroke patients
}

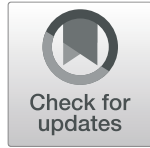

\author{
Nicolas Poupore, Dan Strat, Tristan Mackey, Katherine Brown, Ashley Snell and Thomas I. Nathaniel ${ }^{*}$ (i)
}

\begin{abstract}
Background: Specific clinical risk factors may contribute to improving or worsening neurological functions in acute ischemic stroke (AIS) patients pre-treated with a combined cholesterol reducer and recombinant tissue plasminogen activator (rtPA) therapy. In this study, clinical risk factors associated with good or poor presenting neurological symptoms in ischemic stroke patients with prior cholesterol reducer use, specifically a statin and rtPA therapy was investigated.

Methods: Retrospective data for baseline clinical and demographic data for patients with AIS taking cholesterol reducers prior to rtPA treatment from January 2010 to June 2016 in a regional stroke center was analyzed.

Improving (NIHSS score $\leq 7$ ) or worsening (NIHSS score $>7$ ) of neurologic functions were the determined measures of treatment outcome. Multivariate logistic regression models identified demographic and clinical factors associated with worsening or improving neurologic functions.

Results: Adjusted multivariate analysis showed that in an AIS population with a combined rtPA and cholesterol reducer medication history, increasing age $(\mathrm{OR}=1.032,95 \% \mathrm{Cl}, 1.015-1.048, P<0.001)$ and atrial fibrillation $(\mathrm{OR}=$ $1.859,95 \% \mathrm{Cl}, 1.098-3.149, P=0.021)$ demonstrated a likely association with worsening neurologic functions, while direct admission $(\mathrm{OR}=0.411,95 \% \mathrm{Cl}, 0.246-0.686, P=0.001)$ and being Caucasian $(\mathrm{OR}=0.496,95 \% \mathrm{Cl}, 0.297-0.827$, $P=0.007$ ) showed an association with improving or progressing neurologic functions.

Conclusion: A prior cholesterol reducer, namely a statin, plus rtPA combination may be associated with worsening neurological function for elderly AIS patients with atrial fibrillation, while Caucasians directly admitted to a neurology unit are more likely to show an association with progress or improvements in neurologic functions. While combining statin with rtPA treatment may facilitate worsening neurologic functions in elderly AlS patients with atrial fibrillation, they should not be denied of this therapy. The decision to combine statin and rtPA for AIS patients with atrial fibrillation can be done after clinical stabilization following appropriate clinical management.
\end{abstract}

Keywords: Cholesterol reducer, NIHSS score, Neurological deficits, Thrombolytic therapy, Ischemic stroke

\section{Introduction}

The function of cholesterol reducers, such as statins in the primary and secondary prevention of stroke in patients at risk of cerebrovascular events is well established [1-3]. Findings reveal that statins reduce the risk of first and recurrent ischemic strokes $[4,5]$ and may also

\footnotetext{
* Correspondence: nathanit@greenvillemed.sc.edu

University of South Carolina School of Medicine Greenville, 607 Grove Rd, Greenville, SC 29605, USA
}

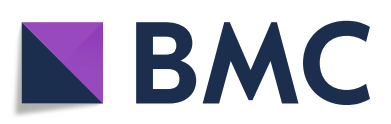

(c) The Author(s). 2020 Open Access This article is licensed under a Creative Commons Attribution 4.0 International License, which permits use, sharing, adaptation, distribution and reproduction in any medium or format, as long as you give appropriate credit to the original author(s) and the source, provide a link to the Creative Commons licence, and indicate if changes were made. The images or other third party material in this article are included in the article's Creative Commons licence, unless indicated otherwise in a credit line to the material. If material is not included in the article's Creative Commons licence and your intended use is not permitted by statutory regulation or exceeds the permitted use, you will need to obtain permission directly from the copyright holder. To view a copy of this licence, visit http://creativecommons.org/licenses/by/4.0/ The Creative Commons Public Domain Dedication waiver (http://creativecommons.org/publicdomain/zero/1.0/) applies to the data made available in this article, unless otherwise stated in a credit line to the data.

improve treatment outcomes through pleiotropic nonstatin-associated effects [6]. Several studies [7-12] report the relationship between statin use and stroke, including related treatment outcomes. While some studies [13-15] report contradictory evidence that cholesterol reducers, including statins, do not reduce initial stroke severity, other studies [16-18] report favorable outcomes associated with statin use and stroke. Findings from the aforementioned studies suggest that specific clinical risk 
factors may combine with the statins to contribute to either the reported favorable or unfavorable outcomes.

Patients with a National Institute of Health Stroke Scale (NIHSS) score of equal to or less than 7 at the time of admission demonstrate a higher likelihood of making positive neurological progress after an AIS, while NIHSS scores greater than 7 on admission demonstrated a higher probability of worsening neurological function in hemispheric strokes $[19,20]$. Therefore, the baseline NIHSS, stratified by NIHSS scores of $\leq 7$ and $>7$ can be used to assess improvement or non-improvement following thrombolytic therapy for AIS [21, 22]. NIHSS scores have shown to be predictive for any vessel occlusions in the anterior circulation, and cut-off values of NIHSS scores $>7$ from three to $6 \mathrm{~h}$ of stroke onset provided a predictive value of $84.4 \%$ for worsening neurologic functions [22]. In another study [21], major neurological improvements were observed with a NIHSS score of below eight within $24 \mathrm{~h}$ of stroke onset, while a score of $\leq 6$ forecasts a favorable neurological recovery [23]. Although low and high NIHSS score cut-off points are effective predictors for mild or severe neurological outcomes, the NIHSS score is heavily weighted towards hemispheric strokes [24]. Therefore, the current study is focused on clinical risk factors associated with positive or poor presenting neurological symptoms in hemispheric ischemic stroke patients with prior cholesterol reducer use. Specifically, the focus is on a prior statin regimen and recombinant tissue plasminogen activator (rtPA) therapy. Recombinant tissue plasminogen activator is an approved Food and Drug Administration (FDA) thrombolytic agent for the treatment of AIS [25-27], resulting in improved functional outcome in patients treated soon after an AIS [28-36].

Eligibility for rtPA within a population of patients with AIS ranges from 6 to $8 \%[12,13]$. This suggests that specific clinical risk factors may contribute to stroke severity and affect treatment outcome following thrombolytic therapy with or without cholesterol reduction therapy [37-40]. The proportion of ischemic stroke patients with prior cholesterol reduction therapy and treated with rtPA at the time of admission may be different from those lacking prior cholesterol reduction therapy and treated with rtPA. This is possible if more clinical risk factors are associated with improving or worsening neurologic functions following rtPA in patients pretreated with a cholesterol reducer compared to those without a cholesterol reducer. The current study tested the hypothesis that specific clinical risk factors may contribute to improving or worsening neurologic functions in AIS patients with previous cholesterol reducer therapy who were treated with rtPA. Understanding and identifying the specific clinical risk factors associated with worsening neurologic functions associated with a combined rtPA and cholesterol reduction therapy will provide information about the measurable and qualitative risks of rtPA and cholesterol reducer use in ischemic stroke patients. In turn, this could help identify future potential research areas to investigate in order to increase eligibility for rtPA and improve ischemic stroke treatment outcomes.

\section{Methods \\ Study population}

This IRB approved (approval number: 00052571) retrospective study analyzed patients with AIS admitted to the health system of Prisma Health-Upstate in Greenville, South Carolina, USA between January 2010 and June 2016. The analysis included patients that presented within $24 \mathrm{~h}$ of symptom onset with an AIS based on brain magnetic resonance image (MRI) or computer tomography (CT) findings demonstrating early signs of ischemia (loss of gray/white matter distinction, hypodensity, or sulcal swelling) or middle cerebral artery (MCA) hyperdensity. Cholesterol reducer use, specifically a statin in this study, includes an active use at the time of admission, while patients that were not receiving a cholesterol reducer at the time of admission were considered as non-cholesterol reducer users. The stroke registry provided the data on demographics, clinical characteristics, and laboratory values and our previous studies have described the stroke registry [34, 35, 41]. Clinical characteristics of the patients included: atrial fibrillation/atrial flutter, coronary artery disease (CAD), carotid stenosis, depression, diabetes, drug or alcohol abuse, dyslipidemia, family history of stroke, congestive heart failure (CHF), hormone replacement therapy (HRT), hypertension, migraine, obesity, prior stroke, prior trans ischemic attack (TIA), prosthetic heart valve, peripheral vascular disease (PVD), chronic renal disease, sickle cell, sleep apnea, and history of smoking. This study also analyzed patients' ambulatory data. The scores ranged from 0 to 3 in this fashion: undocumented (0), patients not able to ambulate (1), able to ambulate with assistance (2), and able to ambulate independently (3). The validity of the scoring has been described in previous studies [42-45]. Each patients' ambulatory status was tracked and collected on admission, during admission, and after discharge. Ambulation was analyzed at discharge and compared with admission to discern any patient improvement in ambulation. In addition, data were collected on patient demographic variables, which included race, gender, ethnicity, BMI, medication history, and stroke severity (NIHSS) score.

\section{Statistical analysis}

All statistical analyses were determined using the Statistical Package for Social Sciences v 26.0 for Windows 
Table 1 Demographic and clinical characteristics of ischemic stroke patients receiving rtPA or not receiving rtPA. Results for continuous variables are presented as Mean \pm SD, while discrete data are presented as percentage frequency. Pearson's ChiSquare is used to compare differences between demographic and clinical characteristics in rtPA treated groups

\begin{tabular}{llll}
\hline Characteristic & No rtPA group & rtPA group & $P$-value \\
Number of patients & 4142 & 1327 & \\
\hline
\end{tabular}

Age Group: No. (\%)

$<50$
$50-59$
$60-69$
$70-79$
$>=80$
Mean \pm SD
Race: No (\%)
White
Black
Other
Gender: No. (\%)
Female
Male

Hispanic Ethnicity: No. (\%)

BMI: Mean \pm SD

Medical History: No. (\%)

Atrial Fib

Carotid Artery Stenosis

Depression

Diabetes

Drugs or Alcohol

Dyslipidemia

Stroke Family History

Heart Failure

Hormonal

Replacement Therapy

Hypertension

Migraine

Obesity

Previous Stroke

Previous TIA (> 24h)

Prosthetic Heart Valve

Peripheral Vascular

Disease

Chronic Renal Disease

Sickle Cell

Sleep Apnea

Smoker

Medication History: No (\%)
Table 1 Demographic and clinical characteristics of ischemic stroke patients receiving rtPA or not receiving rtPA. Results for continuous variables are presented as Mean \pm SD, while discrete data are presented as percentage frequency. Pearson's ChiSquare is used to compare differences between demographic and clinical characteristics in rtPA treated groups (Continued)

\begin{tabular}{|c|c|c|c|}
\hline Characteristic & No rtPA group & rtPA group & $\boldsymbol{P}$-value \\
\hline Number of patients & 4142 & 1327 & \\
\hline HTN medication & $2851(68.8)$ & $943(71.1)$ & 0.125 \\
\hline Cholesterol Reducer & $1796(43.4)$ & $632(47.6)$ & $0.006^{* a}$ \\
\hline Diabetes medication & $1164(28.1)$ & $331(24.9)$ & $0.025^{* a}$ \\
\hline Antidepressant & $489(11.8)$ & $222(16.7)$ & $<0.001^{* a}$ \\
\hline \multicolumn{4}{|l|}{ Initial NIHSS Score: No (\%) } \\
\hline $0-9$ & $2556(76.3)$ & $733(59.4)$ & $<0.001^{* a}$ \\
\hline $10-14$ & $308(9.2)$ & $199(16.1)$ & \\
\hline $15-20$ & $308(9.2)$ & $193(15.6)$ & \\
\hline $21-25$ & $180(5.4)$ & $110(8.9)$ & \\
\hline Mean $\pm S D$ & $7.43 \pm 8.11$ & $10.55 \pm 8.18$ & $<0.001^{* b}$ \\
\hline \multicolumn{4}{|l|}{ Lab values: Mean \pm SD } \\
\hline Total cholesterol & $173.01 \pm 53.6$ & $168.66 \pm 46.48$ & $0.006^{* b}$ \\
\hline Triglycerides & $\begin{array}{l}139.25 \pm \\
104.13\end{array}$ & $\begin{array}{l}140.71 \pm \\
107.94\end{array}$ & 0.674 \\
\hline $\mathrm{HDL}$ & $41.77 \pm 13.91$ & $41.8 \pm 13.65$ & 0.946 \\
\hline LDL & $105.39 \pm 42.06$ & $102.52 \pm 39.07$ & $0.029^{* b}$ \\
\hline Lipids & $6.64 \pm 2.83$ & $6.25 \pm 1.6$ & $<0.001^{* \mathrm{~b}}$ \\
\hline Blood Glucose & $149.22 \pm 82.86$ & $141.29 \pm 74.84$ & $0.001^{* b}$ \\
\hline Serum Creatinine & $1.34 \pm 1.27$ & $1.14 \pm 0.75$ & $<0.001^{* b}$ \\
\hline Initial Platelet Count & $\begin{array}{l}36,527.8 \pm \\
87,310.62\end{array}$ & $\begin{array}{l}174,859.69 \pm \\
128,632.87\end{array}$ & $<0.001^{* b}$ \\
\hline INR & $1.17 \pm 0.57$ & $1.06 \pm 0.15$ & $<0.001^{* b}$ \\
\hline \multicolumn{4}{|l|}{ Vital Signs: Mean \pm SD } \\
\hline Heart Rate & $82.07 \pm 18.94$ & $81.81 \pm 17.18$ & 0.644 \\
\hline Blood Pressure Systolic & $151.99 \pm 30.04$ & $151.31 \pm 26.92$ & 0.439 \\
\hline Blood Pressure Diastolic & $82.29 \pm 19.38$ & $82.92 \pm 18.3$ & 0.277 \\
\hline
\end{tabular}

Ambulation Status

Prior to Event: No. (\%)

$\begin{array}{llll}\text { Ambulate Independently } & 3628(87.6) & 1259(94.9) & <0.001^{* a} \\ \text { Ambulate with Assistance } & 180(4.3) & 23(1.7) & \\ \text { Unable to Ambulate } & 193(4.7) & 20(1.5) & \\ \text { Not Documented } & 140(3.4) & 25(1.9) & \\ \begin{array}{l}\text { Ambulation Status on } \\ \text { Admission: No. (\%) }\end{array} & & & \\ \text { Ambulate Independently } & 1099(26.5) & 232(17.5) & <0.001^{* a} \\ \text { Ambulate with Assistance } & 1320(31.9) & 306(23.1) & \\ \text { Unable to Ambulate } & 1249(30.2) & 479(36.1) & \\ \text { Not Documented } & 474(11.4) & 310(23.4) & \\ \text { Ambulation Status on } & & & \\ \text { Discharge: No. (\%) } & & & \\ \text { Ambulate Independently } & 1516(36.6) & 658(49.6) \\ \text { Ambulate with Assistance } & 1466(35.4) & 354(26.7) & <0.001^{* a} \\ \text { Unable to Ambulate } & 847(20.4) & 222(16.7)\end{array}$


Table 1 Demographic and clinical characteristics of ischemic stroke patients receiving rtPA or not receiving rtPA. Results for continuous variables are presented as Mean \pm SD, while discrete data are presented as percentage frequency. Pearson's ChiSquare is used to compare differences between demographic and clinical characteristics in rtPA treated groups (Continued)

\begin{tabular}{|c|c|c|c|}
\hline Characteristic & No rtPA group & rtPA group & $\boldsymbol{P}$-value \\
\hline Number of patients & 4142 & 1327 & \\
\hline Not Documented & $19(0.5)$ & $4(0.3)$ & \\
\hline \multicolumn{4}{|l|}{ First Care Received: No. (\%) } \\
\hline Emergency Department & $3285(80.1)$ & $1012(76.6)$ & $0.006^{* a}$ \\
\hline Direct Admission & 815 (19.9) & $309(23.4)$ & \\
\hline $\begin{array}{l}\text { Improved Ambulation: } \\
\text { No. (\%) }\end{array}$ & $1141(29.7)$ & $684(55.3)$ & $<0.001^{* a}$ \\
\hline NIHSS > 7: No. (\%) & 1177 (33.5) & $690(52.4)$ & $<0.001^{* a}$ \\
\hline
\end{tabular}

(SPSS, Chicago, IL). The differences between the 2 groups stratified according to cholesterol reducer use prior to the stroke and by stroke severity, with NIHSS scores of $>7$ representing worsening neurologic functions and NIHSS scores $\leq 7$ represent neurologic improvement, was determined. Univariate statistical analysis was performed to determine factors associated with neurologic improvement or worsening stratified by rtPA and prior cholesterol reducer use. In the univariate analysis, the Pearson $x^{2}$ test analyzed discrete variables while the Student's $t$ test analyzed data for all continuous variables. To identify independent predictors of neurologic improvement or worsening, multivariate analyses were then performed to establish predictors (demographic and clinical variables) from the variables in the univariate analysis that had a probability value $P<0.2$ [46]. Because of the nonrandomized design of the study, a post hoc adjusted analysis using logistic regression was performed to determine the most influential variables using the backward selection method. This approach allowed all the variables that were approaching significance to be selected and then systematically removed if a variable did not add to the significance of the model overall. Odds ratios (ORs) predicted the odds of having a higher NIHSS score in association with a combined thrombolytic and cholesterol reduction therapy.

In the regression model, the dependent variable, the NIHSS score stratification, assessed the degree of stroke severity. The primary independent variables in the regression model for the entire AIS population included all the demographic and clinical risk factors for the rtPA and prior cholesterol reducer use group compared to the rtPA without prior cholesterol reducer use group. The odds of developing worsening neurological functions (NIHSS score $>7$ ) and for making progress or improvements (NIHSS score $\leq 7$ ) were analyzed separately for the group who received rtPA (independent of cholesterol reducer use status), rtPA without cholesterol reducer use, and rtPA with cholesterol reducer use. Multicollinearity to determine interactions among independent variables was analyzed using the Hosmer-Lemeshow test. Overall correct classification percentage and area under the Receiver Operating Curve (ROC) determined the sensitivity, specificity, and accuracy of the logistic regression model. Logistic regression determined odd ratios and $95 \%$ confidence intervals $(95 \% \mathrm{CI})$ of outcome measures. These odds ratios predicted which independent variables positively or negatively influenced a patient with an AIS to make progress or improvement in neurological functions.

\section{Results}

A total of 5469 AIS patients were identified. In this population, 1608 patients were eligible for rtPA and 1327 of these received rtPA (Table 1). Of the patients treated with rtPA, 630 were taking a cholesterol reducer prior to the event, whereas 687 were not. As presented in Table 1, the rtPA treated subset of patients were younger $(65.8 \pm 14.8$ vs. $67.7 \pm 14.7)$, more likely to be Hispanic $(2.3 \%$ vs. $1.3 \%)$ and have a higher BMI $(28.18 \pm 7.01$ vs. $28.84 \pm 6.84)$. This group presented with lower rates of carotid stenosis $(4.2 \%$ vs. $6.7 \%)$ and diabetes ( $31.3 \%$ vs. $36.7 \%)$ but had higher rates of depression (15.4\% vs. $12.5 \%)$ and dyslipidemia $(52.8 \%$ vs. $49.6 \%)$. Furthermore, the rtPA group was more likely to be on HRT $(2.3 \%$ vs. $1.2 \%)$, suffer from migraines (3.4\% vs. $2.1 \%)$, and be obese (51.1 vs. 39.4). This group presented with fewer prior strokes $(21.9 \%$ vs. $27.4 \%)$, but a greater history of TIAs (10.8 vs. $8.1 \%)$. They were less likely to have PVD $(6.0 \%$ vs. $7.7 \%)$ and chronic renal disease $(6.0 \%$ vs. $8.9 \%)$ but were more likely to be taking cholesterol reducing agents $(47.6 \%$ vs. $43.4 \%)$ and antidepressants $(16.7 \%$ vs. $11.8 \%)$. The rtPA group was taking fewer antidiabetic medications $(24.9 \%$ vs. $28.1 \%)$ and presented with higher NIHSS scores $(9.95 \pm 6.6$ vs. $7.82 \pm 6.8)$. This group also presented with lower levels of serum cholesterol $(168.7 \pm 46.5$ $\mathrm{mg} / \mathrm{dL}$ vs. $173.0 \pm 53.6 \mathrm{mg} / \mathrm{dL}$ ), creatinine concentrations $(1.14 \pm 0.75 \mathrm{mg} / \mathrm{dL}$ vs. $1.34 \pm 1.27 \mathrm{mg} / \mathrm{dL})$, and blood glucose $(141.3 \pm 74.8 \mathrm{mg} / \mathrm{dL}$ vs. $149.2 \pm 82.9 \mathrm{mg} /$ $\mathrm{dL}$ ) when compared to the non rtPA group. Moreover, the rtPA group differed significantly on ambulation classification prior to stroke, on admission, and on discharge. Patients in the rtPA group were more likely to be directly admitted to the hospital (23.4\% 
Table 2 Demographic and clinical characteristics of ischemic stroke patients treated with rtPA in combination with a cholesterol reducer, or no cholesterol reducer and with worsening neurologic functions (NIHSS score $>7$ ) and neurologic improvements (NIHSS score $\leq 7)$. Results for continuous variables are presented as Mean \pm SD, while discrete data are presented as percentage frequency. Pearson's Chi-Square is used to compare differences between demographic and clinical characteristics in groups with a NIHSS score $>7$ and NIHSS score $\leq 7$ who received rtPA and either took or did not take a cholesterol reducer

\begin{tabular}{|c|c|c|c|c|c|c|}
\hline \multirow[b]{2}{*}{ Characteristic } & \multicolumn{2}{|c|}{ rtPA with Cholesterol Reducer } & & \multicolumn{2}{|c|}{ rtPA without Cholesterol Reducer } & \\
\hline & $\mathrm{NIHSS} \leq 7$ & $\mathrm{NIHSS}>7$ & & $\mathrm{NIHSS} \leq 7$ & $\mathrm{NIHSS}>7$ & \\
\hline Number of patients & 321 & 309 & P-value & 306 & 381 & $P$-Value \\
\hline \multicolumn{7}{|l|}{ Age Group: No. (\%) } \\
\hline$<50$ years & $32(10.0)$ & $20(6.5)$ & $<0.001^{* a}$ & $79(25.8)$ & $60(15.7)$ & $<0.001^{* a}$ \\
\hline $50-59$ & $59(18.4)$ & $44(14.2)$ & & $75(24.5)$ & $80(21.0)$ & \\
\hline $60-69$ & $103(32.1)$ & $73(23.6)$ & & $71(23.2)$ & $67(17.6)$ & \\
\hline $70-79$ & $81(25.2)$ & $76(24.6)$ & & $49(16.0)$ & $80(21.0)$ & \\
\hline$>=80$ & $46(14.3)$ & $96(31.1)$ & & $32(10.5)$ & $94(24.7)$ & \\
\hline Age Mean $\pm S D$ & $\begin{array}{l}65.95 \pm \\
12.09\end{array}$ & $\begin{array}{l}70.83 \pm \\
13.26\end{array}$ & $<0.001^{* b}$ & $\begin{array}{l}59.67 \pm \\
15.47\end{array}$ & $\begin{array}{l}66.31 \pm \\
15.82\end{array}$ & $<0.001^{* b}$ \\
\hline \multicolumn{7}{|l|}{ Race: No (\%) } \\
\hline White & $277(86.3)$ & $244(79.0)$ & $0.050^{* a}$ & $243(79.4)$ & $287(75.3)$ & 0.446 \\
\hline Black & $37(11.5)$ & $56(18.1)$ & & $54(17.6)$ & $80(21.0)$ & \\
\hline Other & $7(2.2)$ & $9(2.9)$ & & $9(2.9)$ & $14(3.7)$ & \\
\hline \multicolumn{7}{|l|}{ Gender: No. (\%) } \\
\hline Female & $130(40.5)$ & $159(51.5)$ & $0.006^{* a}$ & $159(52.0)$ & $205(53.8)$ & 0.630 \\
\hline Male & $191(59.5)$ & $150(48.5)$ & & $147(48.0)$ & $176(46.2)$ & \\
\hline Hispanic Ethnicity: No. (\%) & $7(2.2)$ & $8(2.6)$ & 0.737 & $5(1.6)$ & $10(2.6)$ & 0.377 \\
\hline BMI: Mean \pm SD & $\begin{array}{l}29.72 \pm \\
6.67\end{array}$ & $\begin{array}{l}28.94 \pm \\
7.72\end{array}$ & 0.180 & $\begin{array}{l}29.07 \pm \\
6.72\end{array}$ & $\begin{array}{l}27.83 \pm \\
6.24\end{array}$ & $0.014^{* b}$ \\
\hline \multicolumn{7}{|l|}{ Medical History: No. (\%) } \\
\hline Atrial Fib & 37 (11.5) & $74(23.9)$ & $<0.001^{* a}$ & $35(11.4)$ & $62(16.3)$ & 0.070 \\
\hline Coronary Artery Disease & $135(42.1)$ & $135(43.7)$ & 0.679 & $50(16.3)$ & $74(19.4)$ & 0.296 \\
\hline Carotid Artery Stenosis & $24(7.5)$ & $17(5.5)$ & 0.315 & $4(1.3)$ & $11(2.9)$ & 0.159 \\
\hline Depression & $58(18.1)$ & $60(19.4)$ & 0.664 & $39(12.7)$ & $48(12.6)$ & 0.954 \\
\hline Diabetes & $135(42.1)$ & $124(40.1)$ & 0.623 & $66(21.6)$ & $86(22.6)$ & 0.753 \\
\hline Drugs or Alcohol & $14(4.4)$ & $19(6.1)$ & 0.314 & $15(4.9)$ & $28(7.3)$ & 0.188 \\
\hline Dyslipidemia & $273(85.0)$ & $265(85.8)$ & 0.800 & $75(24.5)$ & $81(21.3)$ & 0.312 \\
\hline Stroke Family History & $45(14.0)$ & $22(7.1)$ & $0.005^{* a}$ & $39(12.7)$ & $24(6.3)$ & $0.004^{* a}$ \\
\hline Heart Failure & $31(9.7)$ & $47(15.2)$ & $0.034^{* a}$ & $16(5.2)$ & $41(10.8)$ & $0.009^{* a}$ \\
\hline Hormonal Replacement Therapy & $10(3.1)$ & $7(2.3)$ & 0.510 & $8(2.6)$ & $6(1.6)$ & 0.338 \\
\hline Hypertension & $291(90.7)$ & $289(93.5)$ & 0.182 & $182(59.5)$ & $273(71.7)$ & $0.001^{* a}$ \\
\hline Migraine & $11(3.4)$ & $7(2.3)$ & 0.382 & $19(6.2)$ & $8(2.1)$ & $0.006^{* a}$ \\
\hline Obesity & $187(58.3)$ & $146(47.2)$ & $0.006^{* a}$ & $172(56.2)$ & $173(45.4)$ & $0.005^{* a}$ \\
\hline Previous Stroke & $90(28.0)$ & $90(29.1)$ & 0.762 & $46(15.0)$ & $62(16.3)$ & 0.657 \\
\hline Previous TIA (> $24 \mathrm{~h})$ & $45(14.0)$ & $41(13.3)$ & 0.784 & $25(8.2)$ & $30(7.9)$ & 0.887 \\
\hline Prosthetic Heart Valve & $2(0.6)$ & $4(1.3)$ & 0.386 & $1(0.3)$ & $3(0.8)$ & 0.430 \\
\hline Peripheral Vascular Disease & $25(7.8)$ & $25(8.1)$ & 0.888 & $12(3.9)$ & $16(4.2)$ & 0.855 \\
\hline Chronic Renal Disease & $23(7.2)$ & $24(7.8)$ & 0.774 & $11(3.6)$ & $21(5.5)$ & 0.236 \\
\hline Sleep Apnea & $16(5.0)$ & $15(4.9)$ & 0.940 & $9(2.9)$ & $5(1.3)$ & 0.133 \\
\hline Smoker & 88 (27.4) & $69(22.3)$ & 0.140 & $117(38.2)$ & $111(29.1)$ & $0.012^{* a}$ \\
\hline
\end{tabular}

Medication History: No (\%) 
Table 2 Demographic and clinical characteristics of ischemic stroke patients treated with rtPA in combination with a cholesterol reducer, or no cholesterol reducer and with worsening neurologic functions (NIHSS score $>7$ ) and neurologic improvements (NIHSS score $\leq 7)$. Results for continuous variables are presented as Mean \pm SD, while discrete data are presented as percentage frequency. Pearson's Chi-Square is used to compare differences between demographic and clinical characteristics in groups with a NIHSS score $>7$ and NIHSS score $\leq 7$ who received rtPA and either took or did not take a cholesterol reducer (Continued)

\begin{tabular}{|c|c|c|c|c|c|c|}
\hline \multirow[b]{2}{*}{ Characteristic } & \multicolumn{2}{|c|}{ rtPA with Cholesterol Reducer } & & \multicolumn{2}{|c|}{ rtPA without Cholesterol Reducer } & \\
\hline & $\mathrm{NIHSS} \leq 7$ & $\mathrm{NIHSS}>7$ & & $\mathrm{NIHSS} \leq 7$ & $\mathrm{NIHSS}>7$ & \\
\hline HTN medication & $286(89.1)$ & $283(91.6)$ & 0.291 & $150(49.0)$ & $216(56.7)$ & $0.045^{* a}$ \\
\hline Diabetes medication & $117(36.4)$ & $106(34.3)$ & 0.574 & $45(14.7)$ & $60(15.7)$ & 0.706 \\
\hline Antidepressant & 63 (19.6) & $64(20.7)$ & 0.734 & $44(14.4)$ & $51(13.4)$ & 0.708 \\
\hline \multicolumn{7}{|l|}{ Lab values: Mean \pm SD } \\
\hline Total cholesterol & $155.76 \pm 41.36$ & $153.88 \pm 46.06$ & 0.598 & $184.85 \pm 46.97$ & $178.75 \pm 43.84$ & 0.087 \\
\hline Triglycerides & $149.43 \pm 115.24$ & $133.22 \pm 100.57$ & 0.067 & $153.54 \pm 119.4$ & $128.33 \pm 95.18$ & $0.003^{* b}$ \\
\hline $\mathrm{HDL}$ & $39.51 \pm 11.76$ & $40.65 \pm 12.61$ & 0.250 & $42.49 \pm 15.41$ & $44.19 \pm 14.03$ & 0.140 \\
\hline LDL & $91.22 \pm 34.93$ & $88.74 \pm 37.96$ & 0.404 & $116.22 \pm 38.58$ & $112.65 \pm 37.26$ & 0.230 \\
\hline Lipids & $6.37 \pm 1.61$ & $6.33 \pm 1.45$ & 0.727 & $6.17 \pm 1.69$ & $6.17 \pm 1.65$ & 0.973 \\
\hline Blood Glucose & $136.22 \pm 63.35$ & $147.04 \pm 73.66$ & $0.049^{* b}$ & $138.19 \pm 81.28$ & $143.76 \pm 79.88$ & 0.372 \\
\hline Serum Creatinine & $1.15 \pm 0.54$ & $1.21 \pm 0.79$ & 0.233 & $1.04 \pm 0.4$ & $1.16 \pm 1.04$ & $0.036^{* b}$ \\
\hline Initial Platelet Count & $\begin{array}{l}159,087.99 \pm \\
131,106.09\end{array}$ & $\begin{array}{l}170,621 \cdot 77 \pm \\
120,785 \cdot 15\end{array}$ & 0.519 & $\begin{array}{l}196,175.97 \pm \\
133,607.09\end{array}$ & $\begin{array}{l}175,315.17 \pm \\
128,742.52\end{array}$ & 0.245 \\
\hline INR & $1.04 \pm 0.12$ & $1.07 \pm 0.12$ & $0.005^{* b}$ & $1.04 \pm 0.15$ & $1.07 \pm 0.18$ & $0.016^{* b}$ \\
\hline \multicolumn{7}{|l|}{ Vital Signs: Mean \pm SD } \\
\hline Heart Rate & $79.62 \pm 15.03$ & $81.31 \pm 17.38$ & 0.191 & $80.71 \pm 16.21$ & $84.98 \pm 18.94$ & $0.002^{* b}$ \\
\hline Blood Pressure Systolic & $150.34 \pm 25.3$ & $150.94 \pm 26.19$ & 0.768 & $151.62 \pm 28.49$ & $152.87 \pm 27.51$ & 0.561 \\
\hline Blood Pressure Diastolic & $81.42 \pm 16.2$ & $80.44 \pm 17.35$ & 0.465 & $84.92 \pm 19.27$ & $84.82 \pm 19.41$ & 0.941 \\
\hline \multicolumn{7}{|c|}{ Ambulation Status Prior to Event: No. (\%) } \\
\hline Ambulate Independently & $315(98.1)$ & $276(89.3)$ & $<0.001^{* a}$ & $297(97.1)$ & $361(94.8)$ & $0.038^{* a}$ \\
\hline Ambulate with Assistance & $2(0.6)$ & $9(2.9)$ & & $7(2.3)$ & $5(1.3)$ & \\
\hline Unable to Ambulate & $2(0.6)$ & $10(3.2)$ & & $1(0.3)$ & $7(1.8)$ & \\
\hline Not Documented & $2(0.6)$ & $14(4.5)$ & & $1(0.3)$ & $8(2.1)$ & \\
\hline \multicolumn{7}{|c|}{ Ambulation Status on Admission: No. (\%) } \\
\hline Ambulate Independently & $93(29.0)$ & $17(5.5)$ & $<0.001^{* a}$ & $95(31.0)$ & $24(6.3)$ & $<0.001^{* a}$ \\
\hline Ambulate with Assistance & $98(30.5)$ & $50(16.2)$ & & $104(34.0)$ & $52(13.6)$ & \\
\hline Unable to Ambulate & $18(5.6)$ & $198(64.1)$ & & $21(6.9)$ & $238(62.5)$ & \\
\hline Not Documented & $112(34.9)$ & $44(14.2)$ & & $86(28.1)$ & $67(17.6)$ & \\
\hline \multicolumn{7}{|c|}{ Ambulation Status on Discharge: No. (\%) } \\
\hline Ambulate Independently & $224(69.8)$ & $86(27.8)$ & $<0.001^{* a}$ & $217(70.9)$ & $128(33.6)$ & $<0.001^{* a}$ \\
\hline Ambulate with Assistance & $76(23.7)$ & $98(31.7)$ & & $78(25.5)$ & $100(26.2)$ & \\
\hline Unable to Ambulate & $12(3.7)$ & $88(28.5)$ & & $9(2.9)$ & $111(29.1)$ & \\
\hline Not Documented & $1(0.3)$ & $1(0.3)$ & & $0(0.0)$ & $2(0.5)$ & \\
\hline \multicolumn{7}{|l|}{ First Care Received: No. (\%) } \\
\hline Emergency Department & $216(67.3)$ & $261(84.5)$ & $<0.001^{* a}$ & $221(72.7)$ & $310(82.2)$ & $0.003^{* a}$ \\
\hline Direct Admission & $105(32.7)$ & $48(15.5)$ & & $83(27.3)$ & $67(17.8)$ & \\
\hline Improved Ambulation: No (\%) & $177(56.5)$ & $151(55.3)$ & 0.763 & $162(53.3)$ & $193(56.5)$ & 0.399 \\
\hline
\end{tabular}

Notes

aPearson's Chi-Squared test.

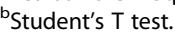

* $P$-value $<0.05$. 
vs. $19.9 \%)$ and have an improved ambulatory status (55.3\% vs. $29.7 \%)$.

Table 2 shows the clinical and demographic characteristics associated with improving or worsening neurologic functions for patients who received rtPA and previously used cholesterol reducers versus those who didn't have a history of cholesterol reducer therapy. In the rtPA with prior cholesterol reducer use group, patients with worsening neurologic functions were older $(70.83 \pm 13.26$ vs. $65.95 \pm 12.09)$, less likely to be Caucasian $(86.3 \%$ vs. $79.0 \%)$, and more likely to be female $(51.5 \%$ vs. $40.5 \%)$, with higher rates of atrial fibrillation $(23.9 \%$ vs. $11.5 \%)$ and heart failure $(15.2 \%$ vs. 9.7\%). This group presented with lower rates of a family history of stroke (7.1\% vs. $14.0 \%)$ and obesity (47.2\% vs. $58.3 \%)$. For laboratory values, the group with worsening neurologic functions who received rtPA presented with higher blood glucose levels $(147.04 \pm 73.66$ vs. $136.22 \pm 63.35)$, higher international normalized ratio (INR) $(1.07 \pm 0.12$ vs. $1.04 \pm 0.12)$ and were more likely to be directly admitted to the hospital (84.5\% vs. $67.3 \%)$. For the rtPA without prior cholesterol reducer use group, the patients with worsening neurologic functions were older $(66.31 \pm 15.82$ vs. $59.67 \pm 15.47)$, presented with lower BMI (27.83 \pm 6.24 vs. $29.07 \pm 6.72$ ), higher rates of heart failure $(10.8 \%$ vs. $5.2 \%)$, hypertension $(71.1 \%$ vs. $59.5 \%)$, and were more likely to be taking anti-hypertensive (antiHTN) medications (56.7\% vs. $49.0 \%$ ). This group presented with lower rates of a family history of stroke $(6.3 \%$ vs. $12.7 \%)$, migraines $(2.1 \%$ vs. $6.2 \%)$, obesity ( $45.4 \%$ vs. $56.2 \%)$ smoking history $(29.1 \%$ vs. $38.2 \%)$ and triglycerides $(128.33 \pm 95$. vs. $153.54 \pm 119.4)$, but higher serum creatinine $(1.16 \pm 1.04$ vs. $1.04 \pm 0.4)$ and higher INR $(1.07 \pm 0.18$ vs. $1.04 \pm 0.15)$. In addition, this group presented with a higher heart rate $(84.98 \pm$ 18.94 vs. $80.71 \pm 16.21)$ and were more likely to be directly admitted to the hospital ( $82.2 \%$ vs. $72.2 \%)$.

The forest plot demonstrating clinical factors that were associated with the severity of stroke for the

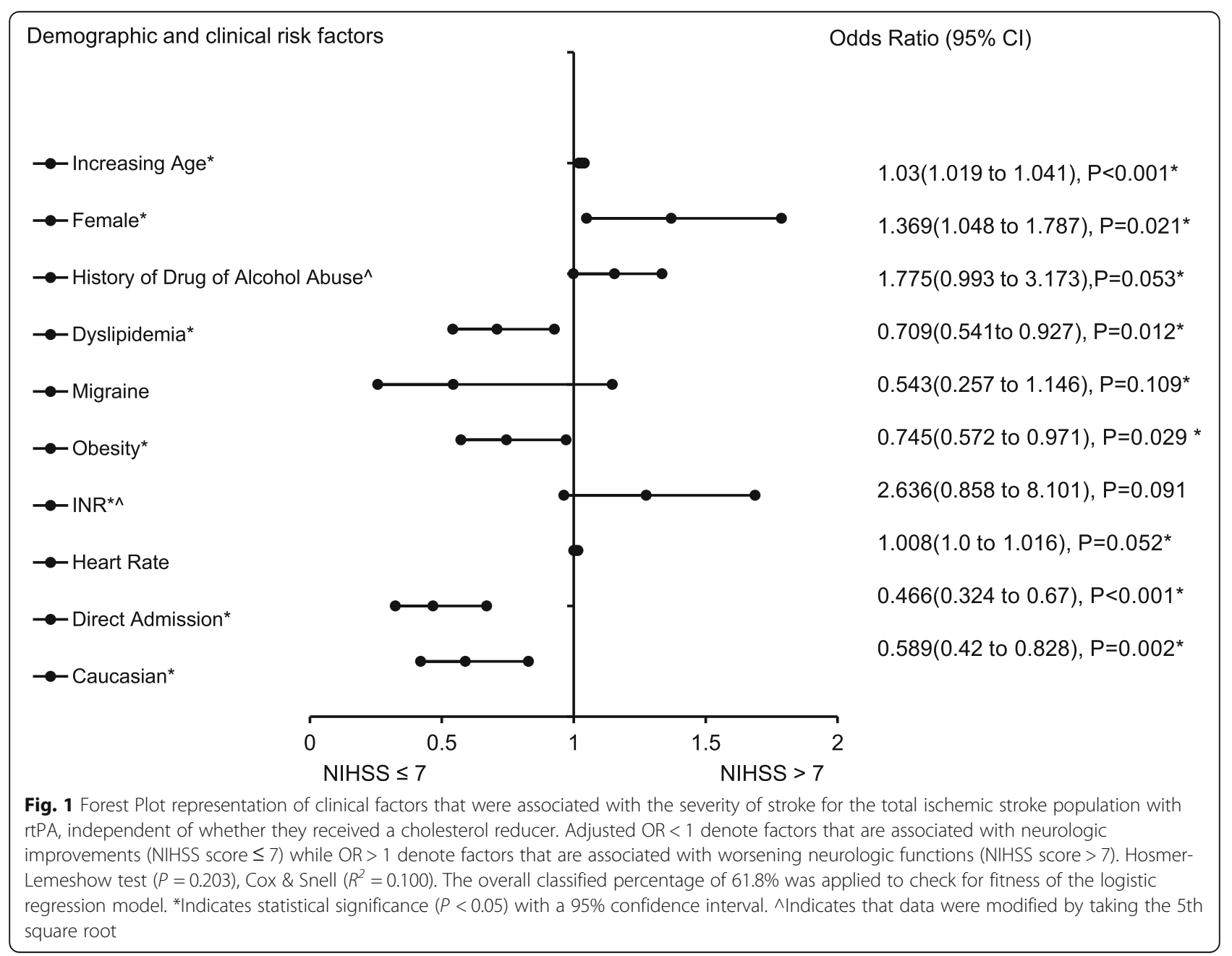


total ischemic stroke population (Fig. 1). In the adjusted analysis, increasing age $(\mathrm{OR}=1.03,95 \% \mathrm{CI}$, $1.019-10.4, P<0.001)$ and being female $(\mathrm{OR}=1.369$, 95\% CI, 1.048-1.787, $P=0.021$ ) were variables associated with worsening neurologic functions, while dyslipidemia (OR $=0.709,95 \% \mathrm{CI}, 0.541-0.927$, $P=0.012$ ), obesity ( $\mathrm{OR}=0.745,95 \% \mathrm{CI}, 0.572-0.971$, $P=0.029)$, direct admission $(\mathrm{OR}=0.466,95 \% \mathrm{CI}$, $0.324-0.670, P<0.001)$, and Caucasian race $(\mathrm{OR}=$ $0.589,95 \% \mathrm{CI}, 0.42-0.828, P=0.002)$ were associated with improving neurologic functions. The discriminating capability of the model was moderately strong as shown by the ROC curve (Fig. 2), with area under the curve (AUROC) $=0.677$ (95\% CI, 0.646-0.707, $P<0.001)$. In the rtPA group without prior cholesterol reducer use (Fig. 3) increasing age $(\mathrm{OR}=1.027$, 95\% CI, 1.014-1.041, $P<0.0 .01)$, higher heart rate $(\mathrm{OR}=1.016,95 \% \mathrm{CI}, 1.005-1.027, P=0.005)$, and improvement in ambulation $(\mathrm{OR}=1.571,95 \% \mathrm{CI}$, $1.078-2.289, P=0.019)$ were associated with neurologic deterioration or worsening neurologic functions. Patients with a family history of stroke $(\mathrm{OR}=$ 0.511, 95\% CI, 0.264-0.99, $P=0.047)$, migraines
(OR $=0.250,95 \% \mathrm{CI}, 0.130-0.943, P=0.038)$, obesity $(\mathrm{OR}=0.685,95 \% \mathrm{CI}, 0.473-0.992, P=0.045)$, direct admission $(\mathrm{OR}=0.512,95 \% \mathrm{CI}, 0.303-0.866, P=$ 0.013), and Caucasian race $(\mathrm{OR}=0.604,95 \% \mathrm{CI}$, $0.381-0.957, P=0.032$ ) were more likely to be associated with a neurologic improvement. As presented in Fig. 4, the predictive power of the logistic regression was moderately strong, as the area under the curve (AUROC) was 0.681 (95\% CI, 0.637-0.724, $P<0.001)$. For the rtPA group with prior cholesterol reducer use (Fig. 5), increasing age (OR $=1.032$, 95\% CI, 1.015-1.048, $P<0.001)$ and atrial fibrillation $(\mathrm{OR}=1.859,95 \% \mathrm{CI}, 1.098-3.149, P=0.021)$ were more likely to be associated with worsening neurologic function. Direct admission $(\mathrm{OR}=0.411,95 \% \mathrm{CI}$, $0.246-0.686, P=0.001)$ and Caucasian race $(\mathrm{OR}=$ $0.496,95 \% \mathrm{CI}, 0.297-0.827, P=0.007)$ were associated with greater neurologic improvement. The ROC curve for the predictive power of the regression model as presented in Fig. 6 shows that the discriminating capability of the model was moderately strong, with the area under the curve $($ AUROC) $=$ 0.680 (95\% CI, 0.639-0.722, $P<0.001$ ).

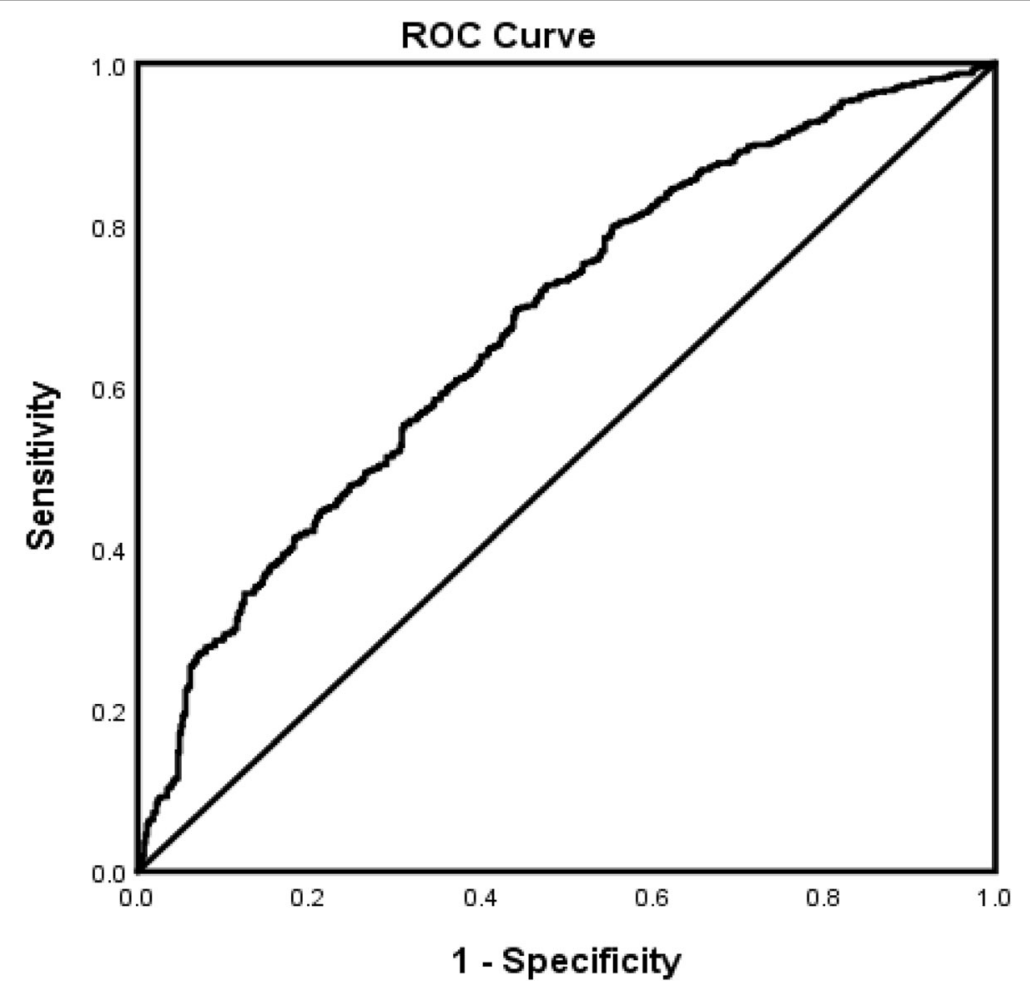

Diagonal segments are produced by ties.

Fig. 2 The ROC curve for the predictive power of the regression model for AIS population with rtPA. Higher area under the curve (AUC) values in ROC analysis indicate better discrimination of the score for the measured outcome. Classification table (overall correctly classified percentage $=$ $61.8 \%$ ) and area under the ROC curve (AUC $=0.677,0.646-0.707$ ) were applied to check model fitness. Andicates that data were modified by taking the 5 th square root 
Demographic and clinical risk factors

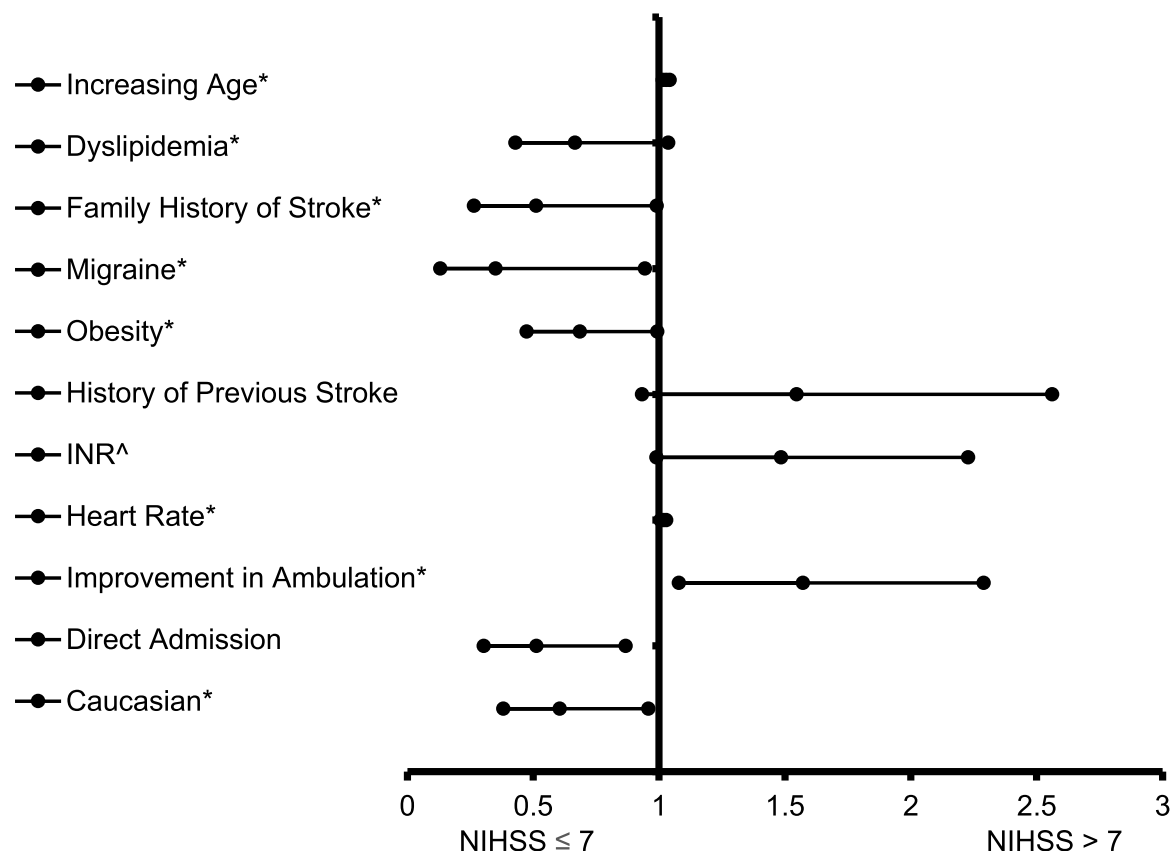

Odds Ratio $(95 \% \mathrm{Cl})$

$1.027(1.014$ to 1.041$), P<0.001$ *

0.665 (0.428 to 1.035$), P=0.07$

$0.511(0.264$ to 0.99$), P=0.047^{*}$

0.35 (0.13 to 0.943$), P=0.038^{*}$

0.685 (0.473 to 0.992$), P=0.045^{*}$

$1.545(0.932$ to 2.561$), P=0.092$

4.853(0.957 to 24.615), $\mathrm{P}=0.057$

1.016(1.005 to 1.027$), P=0.005^{*}$

1.571(1.078 to 2.289$), P=0.019^{*}$

$0.512(0.303$ to 0.866$), P=0.013^{*}$

$0.604(0.381$ to 0.957$), P=0.032^{*}$

Fig. 3 Forest Plot representation for clinical factors that were associated with stroke severities in ischemic stroke population with rtPA only. Adjusted $\mathrm{OR}<1$ denote factors that are associated with neurologic improvements (NIHSS score $\leq 7$ ) while OR $>1$ denote factors that are with worsening neurologic functions (NIHSS score $>7)$. Hosmer-Lemeshow test $(P=0.907)$, Cox \& Snell $\left(R^{2}=0.123\right)$. The overall classified percentage of $65.7 \%$ was applied to check for fitness of the logistic regression model. ${ }^{*}$ Indicates statistical significance $(P<0.05)$ with a $95 \%$ confidence interval. $\wedge$ Indicates that data were modified by taking the 5 th square root

\section{Discussion}

Cholesterol reducers, particularly statins, are known to protect against ischemic injury and could be beneficial in the acute phase of stroke [28], but it remains controversial whether a combined statin and thrombolytic therapy increases the risk of hemorrhage, a major rtPA-related complication. Moreover, specific baseline clinical risk factors may interact with the combined statin and thrombolytic therapy to worsen neurologic functions in AIS patients. The current study investigated specific factors that may contribute to favorable or unfavorable outcomes in a combined statin and thrombolytic therapy.

Our finding indicates that AIS patients without prior cholesterol reduction therapy but received rtPA were more likely to be elderly patients with higher heart rate and are more likely to improve neurologically fowling rtPA therapy. Moreover, AIS patients, with a previous history of stroke, migraines, obesity, direct admission, and Caucasian ethnicity were more likely to exhibit neurologic improvement following thrombolytic therapy. These findings are consistent with a single-center study involving small cohorts which shows that a history of stroke $[47,48]$, migraines [49], obesity [50, 51] and direct admission into the neurological unit [52] were associated with improved functional outcomes following thrombolytic therapy. In addition, our finding that AIS patients without prior cholesterol reducer use who presented with increased age and higher heart rate had a likelihood of worsening neurological function following thrombolytic shows consistency with previous studies $[9,53,54]$.

In the combined rtPA with prior cholesterol reducer use cohort, the effect of increasing age and atrial fibrillation was significant for a worsening neurological function in the AIS patients. Interestingly, studies have shown that rtPA works as effectively in the elderly as in younger patients [55-57]. It has also been shown that age may influence the outcome and risk of hemorrhage after rtPA therapy [58-60]. Therefore, increasing age is associated with an increased number of comorbidities and worse outcomes regardless of rtPA-related complications [61-63]. While studies have not shown age alone to negate the beneficial 


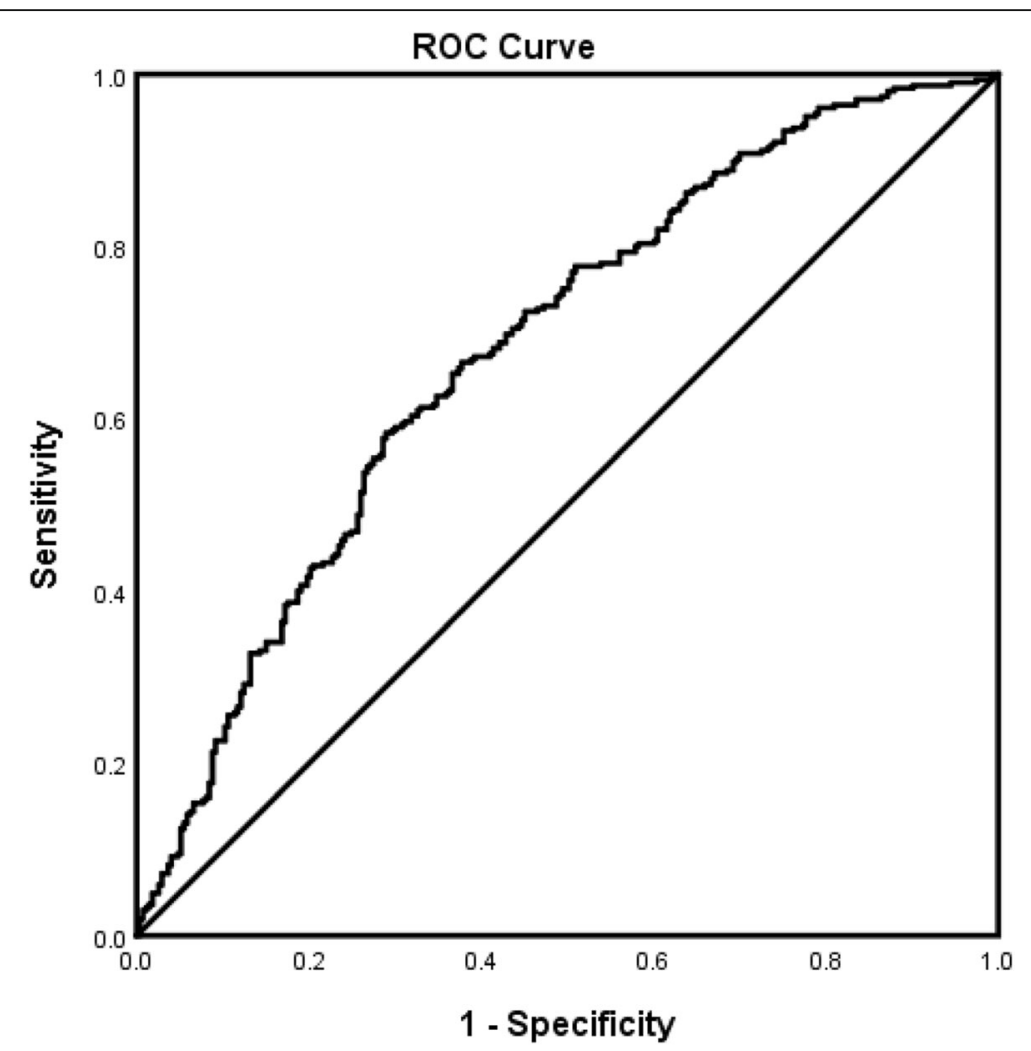

Fig. 4 The ROC curve for the predictive power of the regression model AIS population who received rtPA and were not taking a cholesterol reducer. Higher area under the curve (AUC) values in ROC analysis indicate better discrimination of the score for the measured outcome. Classification table (overall correctly classified percentage $=65.7 \%$ ) and area under the ROC curve (AUC $=0.681,0.637-0.724$ ) were applied to check model fitness. AIndicates that data were modified by taking the 5 th square root

effects of rtPA, the benefits of statins treatment in the elderly is controversial because neurological outcome is associated with many clinical and demographic factors. For example, elderly presents with more comorbidities usually receive a complex treatment regimen consisting of different classes of drugs which may interact with statins and rtPA resulting in worsening neurological outcomes. Therefore, the mechanisms associated with poor outcomes in the interaction between cholesterol reducers and rtPAtreated in elderly AIS patients' needs further evaluation in order to develop management strategies to prevent poor outcomes in elderly AIS patients taking a combined rtPA and statin therapy.

The observed worsening neurologic function in AIS patients with atrial fibrillation treated with the combined cholesterol reducer and rtPA therapy is not surprising as atrial fibrillation has been shown to be associated with worse initial outcomes in patients with ischemic strokes [41, 64]. Statins are known to be effective at reducing the incidence of atrial fibrillation after coronary surgery, but the effectiveness of statins on management of atrial fibrillation is not clear [65]. It has been shown that the development of atrial fibrillation can be due to a NO-redox imbalance in the atria [66]. However, there are two different mechanisms that have been reported to determine whether atrial fibrillation is acute or chronic [66]. Statins in this study [66] were shown to be effective in providing protection from the development of acute atrial fibrillation, but once chronic atrial fibrillation is established, statins were not effective in the long-term management.

Treatment with statins before or early after an ischemic stroke is reported to trigger favorable outcomes [9] through its pleiotropic effects, such as endothelial nitric oxide increase [67], reduction of oxidative stress [68], inhibition of platelet activation [69], and anti-inflammatory activities [70]. These properties suggest statins as a safe and promising pre- or cotreatment with rtPA for an effective reperfusion therapy in the acute phase of stroke [7, 71], However, these benefits are not attributed to a statin's cholesterol lowering effects but are associated with its other pleiotropic effects. Observational studies on cholesterol reducers including statins [72] indicate an 


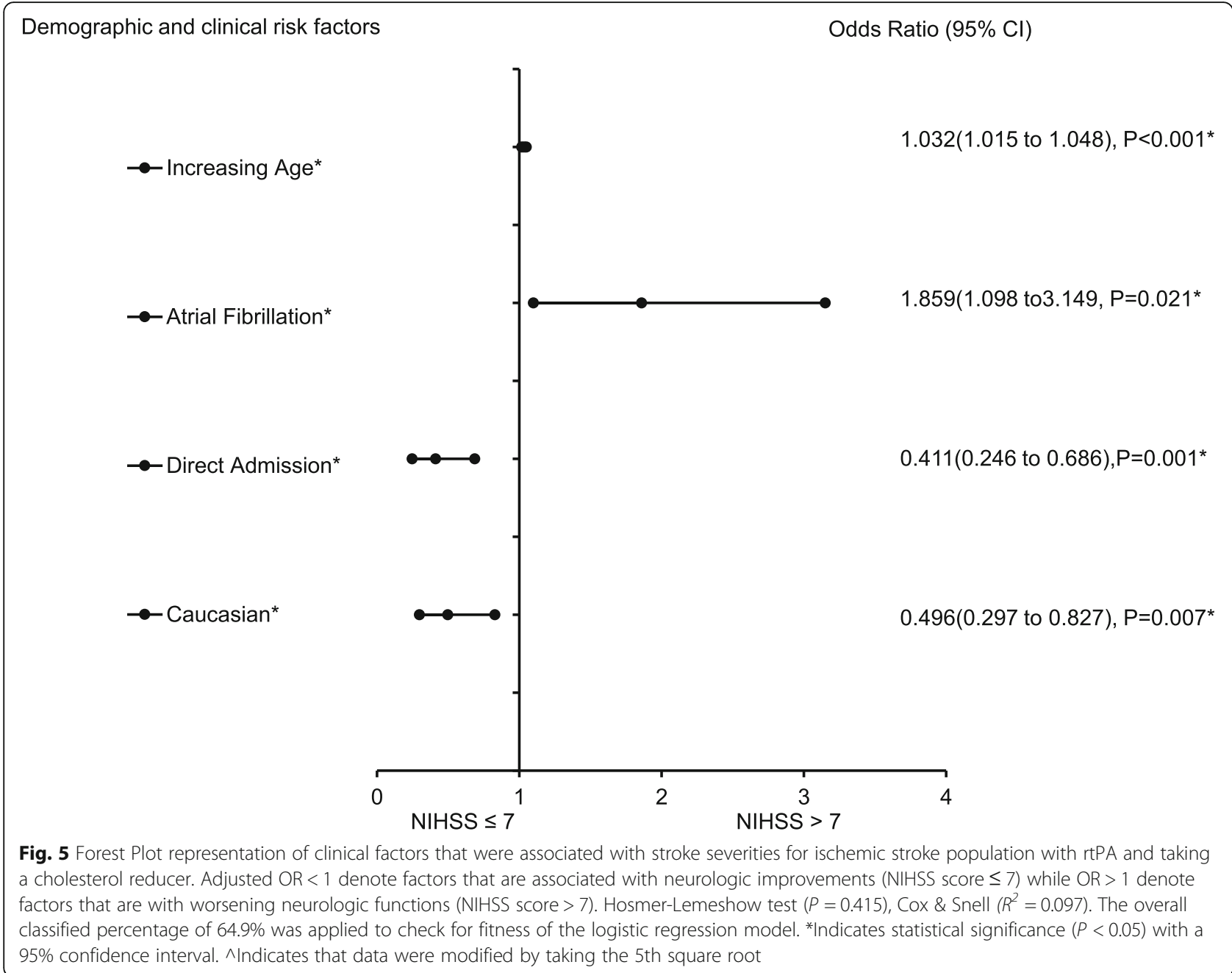

inverse correlation of cholesterol and intracerebral hemorrhage $(\mathrm{ICH})$ risk. This finding indicates that statin treatment maybe associated with an increased risk of $\mathrm{ICH}$ after stroke when combined with rtPA [73]. Statins inhibit the generation of thrombin and disrupts fibrinolytic balance by upregulating endogenous rtPA production and reducing plasminogen activator-inhibitor 1 expression [74]. This results in an enhanced efficacy of rtPA which increases the risk of ICH and other vascular events. Overall, this combination can lead to the induction of several events including ischemic, hemorrhagic activities as well as impairment of vascular events linked with atrial fibrillation which will significantly decrease the chances of good outcome AIS [75]. While cholesterol reducers, and more specifically statins, may be ineffective in the long-term management of atrial fibrillation, combining statin and rtPA treatment should not be denied to patients with AIS patients with atrial fibrillation. Rather, a decision to combine statin and rtPA for AIS patients with atrial fibrillation can be done after clinical stabilization with appropriate risks and benefits.

One of the main strengths of the study is the ability to use a logistic regression model to identify baseline demographic and clinical risk factors that may determine whether AIS patients with prior cholesterol reduction therapy and rtPA therapy with baseline stroke severity are more likely to exhibit neurological improvement or develop worsening neurologic function. Our findings indicate that prior cholesterol reducer usage, namely a statin, in addition to rtPA therapy may be associated with worsening neurologic function for elderly AIS patients with atrial fibrillation, while the statin and rtPA combination in Caucasians and those directly admitted to a neurology unit are more likely to be associated with improvement in neurologic function. This study also presents some 


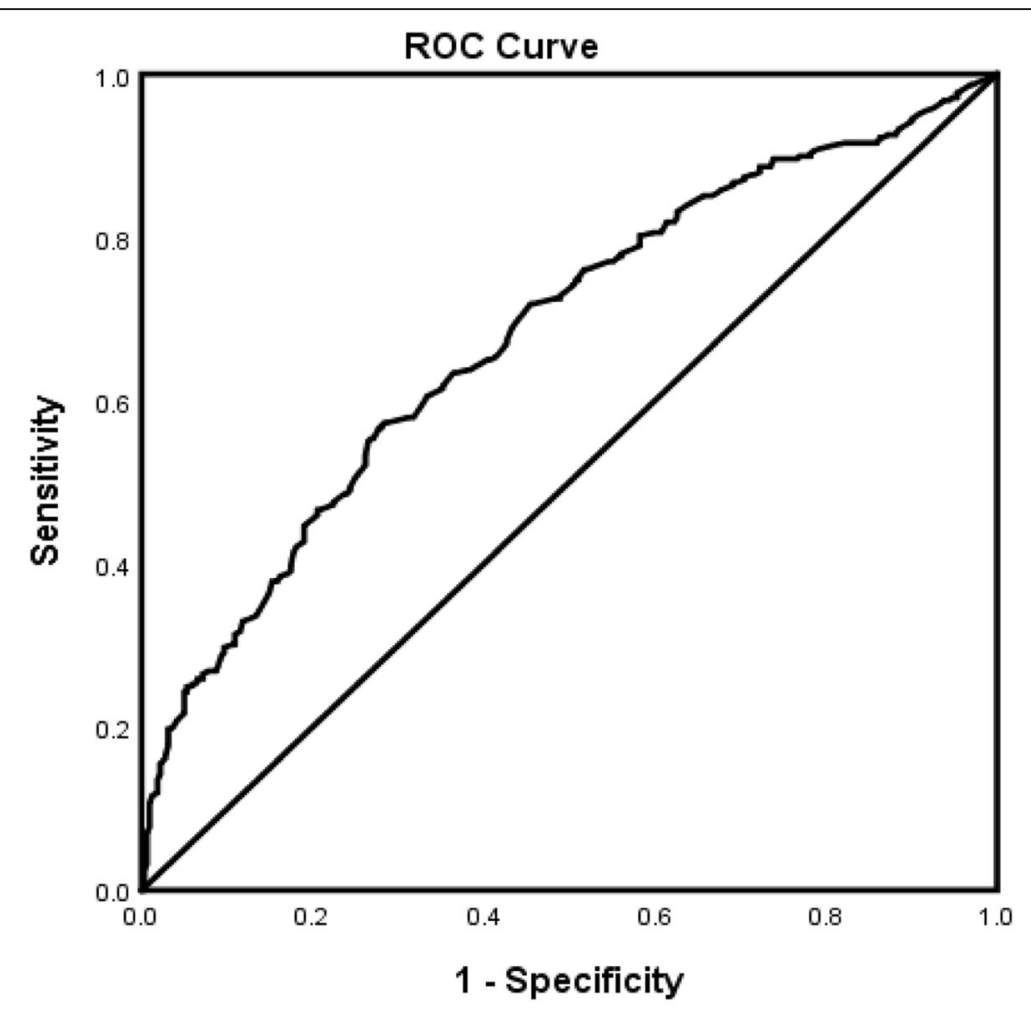

Diagonal segments are produced by ties.

Fig. 6 The ROC curve for the predictive power of the regression model for AIS population who received rtPA and were taking a cholesterol reducer. Higher area under the curve (AUC) values in ROC analysis indicate better discrimination of the score for the measured outcome. Classification table (overall correctly classified percentage $=64.9 \%$ ) and area under the ROC curve (AUC $=0.680,0.639-0.722$ ) were applied to check model fitness. AIndicates that data were modified by taking the 5 th square root

limitations. Because of the retrospective nature of this study, bias should always be considered when trying to draw conclusions. Moreover, while the stroke registry did record the data for patients that take statins versus those who did not, information about other cholesterol reducers and on any patients that suffer health declines of any kind after stopping statin therapy was not included in the data analysis. Therefore, it is difficult to compare the effects that may be due to another type of cholesterol reducer apart from statins or due to the potential heterogenous pool of cholesterol reduction therapy used. Finally, since the stroke registry was only obtained from one hospital, it is challenging to make conclusions about the entire population. However, this study has shown specifically that prior statin use in combination with rtPA therapy in patients with AIS is a promising therapy for Caucasians at early admission only, necessitating more clinical trials in the near future.

\section{Conclusion}

After controlling for demographic and clinical risk factors, older patients with atrial fibrillation who presented with an AIS on pre-stroke cholesterol reduction therapy, namely a statin, and received rtPA were more likely to develop worsening neurologic functions, while Caucasian patients directly admitted to a neurology unit were more likely to develop improving neurologic functions.

\section{Supplementary information}

Supplementary information accompanies this paper at https://doi.org/10. 1186/s12944-020-01270-2.

Additional file 1. A conceptual diagram of our findings implications and underlying mechanism

\section{Abbreviations}

Adjusted OR: Adjusted odd ratio; BMI: Body mass index; CHF: Congestive heart failure; Cl: Confidence interval; INR: International normalized ratio; LDLC: Low-density lipoprotein; rtPA: Recombinant tissue plasminogen; ICH: intracerebral hemorrhage; TC: Total cholesterol; TG: Total glyceride; AIS: Acute ischemic stroke; NIHSS: National institute of health stroke scale; MRI: Magnetic resonance imaging; CT: Computer tomography; MCA: Middle cerebral artery; CAD: Coronary artery disease; HRT: Hormone replacement therapy; TIA: Trans ischemic attack; PVD: Peripheral vascular disease; ROC: Receiver operating curve; INR: International normalized ratio 


\section{Acknowledgements}

We thank the stroke unit of PRISMA Health-Upstate for helping in the data collection.

\section{Authors' contributions}

NP and TIN designed the concept, experiment and data analysis, while DS, $\mathrm{KB}, \mathrm{AS}$ and TM critically revised the drafts, interpreted the results, read and approved the last version of this manuscript.

\section{Funding}

This study was funded by the Fullerton Foundation.

\section{Availability of data and materials}

The retrospective datasets are available by request from the corresponding author of this manuscript.

\section{Ethics approval and consent to participate}

This is a retrospective data collection and analyzed data were de-identified. This study was approved by the institutional review board of PRISMA Health institutional committee for ethics (approval number: 00052571).

\section{Consent for publication}

All authors have provided the corresponding author with permission to be named in the manuscript, approved the submission of this manuscript, and provided consent for this publication.

\section{Competing interests}

All authors declare no conflict of interest.

\section{Received: 7 January 2020 Accepted: 27 April 2020}

\section{Published online: 06 May 2020}

\section{References}

1. Horvath E, Vadasdi K, Vastagh I, Folyovich A. Role of diagnosis of dyslipidemia in primary and secondary vascular prevention in a neurology department. Ideggyogy Sz-Clin Neurosci. 2010;63:121-4.

2. Neau JP, Moumy H, Mathis S, Gil R. Statins and prevention of strokes. Rev Neurol. 2005;161:237-44.

3. Paciaroni M, Hennerici M, Agnelli G, Bogousslavsky J. Statins and stroke prevention. Cerebrovasc Dis. 2007;24:170-82.

4. Castilla-Guerra L, Fernandez-Moreno MD, Colmenero-Camacho MA. Statins in stroke prevention: present and future. Curr Pharm Des. 2016;22:4638-44

5. Elkind MSV. Outcomes after stroke. risk of recurrent ischemic stroke and other events. Am J Med. 2009:122:7-13.

6. Wang CY, Liu PY, Liao JK. Pleiotropic effects of statin therapy: molecular mechanisms and clinical results. Trends Mol Med. 2008;14:37-44.

7. Fang JX, Wang EQ, Wang W, Liu Y, Cheng G. The efficacy and safety of high-dose statins in acute phase of ischemic stroke and transient ischemic attack: a systematic review. Intern Emerg Med. 2017;12:679-87.

8. Aznaouridis K, Masoura C, Vlachopoulos C, Tousoulis D. Statins in stroke. Curr Med Chem. 2019;26:6174-85.

9. Zhao W, Xiao ZJ, Zhao SP. The benefits and risks of statin therapy in ischemic stroke: a review of the literature. Neurol India. 2019;67:983-92.

10. Ziff OJ, Banerjee G, Ambler G, Werring DJ. Statins and the risk of intracerebral haemorrhage in patients with stroke: systematic review and meta-analysis. J Neurol Neurosurg Psychiatry. 2019;90:75-83.

11. Fazzone B, Morris G, Black LA, Williams JA, Leacock R, Sternberg S, Blackhurst D, Nelson A, Nathaniel IT. Exclusion and inclusion criteria for thrombolytic therapy in an ischemic stroke Population.E 4(2): 1112. J Neurol Disord Strok. 2016;4:1-5.

12. Fleming T, Blum B, Averkamp B, Sullivan J, Nathaniel T. Effect of antihypertensive medications on thrombolysis therapy and outcomes in acute ischemic stroke patients. J Clin Hypertens. 2019;21:271-9.

13. Chen XY, Zhuang XR, Peng ZW, Yang HL, Chen LY, Yang QW. Intensive statin therapy for acute ischemic stroke to reduce the number of microemboli: a preliminary, randomized controlled study. Eur Neurol. 2018; 80:163-70.

14. Aboa-Eboule C, Binquet C, Jacquin A, Hervieu M, Bonithon-Kopp C, Durier J, Giroud M, Bejot Y. Effect of previous statin therapy on severity and outcome in ischemic stroke patients: a population-based study. J Neurol. 2013;260:30-7.
15. Asdaghi N, Coulter Jl, Modi J, Camden MC, Qazi A, Goyal M, Rundek T, Coutts SB. Statin therapy does not affect the radiographic and clinical profile of patients with TIA and Minor stroke. Am J Neuroradiol. 2015;36: $1076-80$

16. Yoon SS, Dambrosia J, Chalela J, Ezzeddine M, Warach S, Haymore J, Davis L, Baird AE. Rising statin use and effect on ischemic stroke outcome. BMC Med. 2004;2.

17. Choi JC, Lee JS, Park TH, Cho YJ, Park JM, Kang K, Lee KB, Lee SJ, Ko Y, Lee J, et al. Effect of pre-stroke statin use on stroke severity and early functional recovery: a retrospective cohort study. BMC Neurol. 2015;15.

18. Chen PS, Li YH, Cheng KW, Yang YHK. In-hospital initiation of statins therapy improves the clinical outcomes in patients with acute ischemic stroke. J Am Coll Cardiol. 2009:53:A205.

19. Phuong V, Huy TV. Prediction of acute stroke progression by the National Institutes of Health stroke scale. J Geriatr Cardiol. 2007:4:225-8.

20. DeGraba TJ, Hallenbeck JM, Pettigrew KD, Dutka AJ, Kelly BJ. Progression in acute stroke. Stroke. J Cereb Circ. 1999:30:1208-12.

21. Wouters A, Nysten C, Thijs V, Lemmens R. Prediction of outcome in patients with acute ischemic stroke based on initial severity and improvement in the first 24 h. Front Neurol. 2018;9.

22. Heldner MR, Zubler C, Mattle HP, Schroth G, Weck A, Mono ML, Gralla J, Jung S, El-Koussy M, Ludi R, et al. National Institutes of Health stroke scale score and vessel occlusion in 2152 patients with acute ischemic stroke. Stroke. 2013;44:1153-6.

23. Adams HP, Davis PH, Leira EC, Chang KC, Bendixen BH, Clarke WR, Woolson RF, Hansen MD. Baseline NIH Stroke scale score strongly predicts outcome after stroke - a report of the trial of org 10172 in acute stroke treatment (TOAST). Neurology. 1999;53:126-31.

24. Schneck MJ. Current stroke scales may be partly responsible for worse outcomes in posterior circulation stroke. Stroke. 2018;49:2565-6.

25. Wardlaw JM, Murray V, Berge E, del Zoppo G, Sandercock P, Lindley RL, Cohen G. Recombinant tissue plasminogen activator for acute ischaemic stroke: an updated systematic review and meta-analysis. Lancet. 2012;379:2364-72.

26. Polk S, Stafford C, Adkins A, Efird J, Colello M, Nathaniel IT. Contraindications with recombinant tissue plasminogen activator (rt-PA) in acute ischemic stroke population. Neurol Psychiatry Brain Res. 2018;27:6-11.

27. Fredwall M, Sternberg S, Blackhurst D, Lee A, Leacock R, Nathaniel TI. Gender differences in exclusion criteria for recombinant tissue-type plasminogen activator. J Stroke Cerebrovasc Dis. 2016;25:2569-74.

28. Wapshott T, Blum B, Williams K, Nathaniel IT. Investigation of gender differences and exclusive criteria in a diabetic acute ischemic stroke population treated with recombinant tissue-type plasminogen activator (rtPA). J Vasc Interv Neurol. 2017;9:26-32.

29. Reynolds M, Blum B, Brechtel L, Gainey G, Nathaniel IT. Clinical risk factors associated with functional outcomes of thrombolytic therapy in stroke and non-stroke units. J Exp Stroke Transl Med. 2017;1:22-8.

30. Blum B, Brechtel L, Nathaniel T. Thrombolysis therapy in specialized and non-specialized stroke units. Arch Med Res. 2018;49:588-97.

31. Blum B, Penwell A, Wormack L, Walker B, Lari S, Nathaniel TI. Gender and thrombolysis therapy in acute ischemic stroke patients with incidence of obesity. Neurol Sci. 2019:40:1829-39.

32. Colello MJ, Ivey LE, Gainey J, Faulkner RV, Johnson A, Brechtel L, Madeline L, Nathaniel T1. Pharmacological thrombolysis for acute ischemic stroke treatment: gender differences in clinical risk factors. Adv Med Sci. 2018;63:100-6.

33. Nathaniel IT, Gainey J, Blum B, Montgomery C. Clinical risk factors in thrombolysis therapy: Telestroke versus Nontelestroke. J Stroke Cerebrovasc Dis. 2018;78:90-8.

34. Nathaniel IT, Williams J, Fazzone F, Yi S, Morris G, Black L, Fredwall M, Staford C, Adkins A, Polk S. Contraindications and exclusion criteria in guidelines for Rt-pa in acute ischemic stroke: can the new aha/asa guideline expand the use of Rt-pa? Hypertension. 2016:245-347.

35. Nathaniel TI, Cochran T, Chaves J, Fulmer E, Sosa C, Yi S, Fredwall M, Sternberg S, Blackhurst D, Nelson A, Leacock R. Co-morbid conditions in use of recombinant tissue plasminogen activator (rt-PA) for the treatment of acute ischaemic stroke. Brain Inj. 2016;30:1261-5.

36. Nathaniel TI, Gainey J, Blum B, Montgomery C, Ervin L, Madeline L. Clinical risk factors in thrombolysis therapy. Telestroke versus Nontelestroke. J Stroke Cerebrovasc Dis. 2018;27:2524-33.

37. Blum B, Wormack L, Holtel M, Penwell A, Lari S, Walker B, Nathaniel TI. Gender and thrombolysis therapy in stroke patients with incidence of dyslipidemia. BMC Womens Health. 2019:19-29. 
38. Gainey J, Blum B, Bowie B, Cooley K, Madeline L, Lowther E, Nathaniel IT. Stroke with dyslipidemia: Clinical risk factors in the telestroke versus nontelestroke. Lipids Health Dis. 2018;4:123-48.

39. Gainey J, Brechtel L, Konklin S, Madeline E, Lowther E, Blum B, Nathaniel IT. In a stroke cohort with incident hypertension; are more women than men likely to be excluded from recombinant tissue-type Plasminogen Activator (rtPA)? J Neurol Sci. 2018:387:139-46.

40. Gainey J, Brecthtel L, Blum B, Keels A, Madeline L, Lowther E, Nathaniel $T$. Functional outcome measures of recombinant tissue plasminogen activator-treated stroke patients in the telestroke technology. J Exp Neurosci. 2018:12:86-94.

41. Nathaniel TI, Ubah C, Wormack L, Gainey J. The telestroke and thrombolysis therapy in diabetic stroke patients. Diabetol Metab Syndr. 2019;11:98-110.

42. Lawson TR, Brown IE, Westerkam DL, Blackhurst DW, Sternberg S, Leacock R, Nathaniel TI. Tissue plasminogen activator (rt-PA) in acute ischemic stroke: outcomes associated with ambulation. Restor Neurol Neurosci. 2015;33:301-8.

43. Oluyemi RR, Ajani IF, Penwell A, Lari S, Walker B, Nathaniel IT. In acute ischemic stroke patients with a history of smoking; are more women than men more likely to be excluded from thrombolysis therapy? Women Health. 2020;32:67-74.

44. Okon M, Adebobola NI, Julius S, Adebimpe O, Taiwo AO, Akinyemi A, Thomas NI. Stroke incidence and case fatality rate in an urban population. J Stroke Cerebrovasc Dis. 2015;24:771-7.

45. Okon M, Blum B, Bailes B, Nathaniel T. Thrombolytic therapy and risk factors in ischemic stroke patients with pre-stroke depression. Neurosci Insights. 2020.

46. Zhang ZH. Model building strategy for logistic regression: purposeful selection. Ann Transl Med. 2016:4:94-110.

47. Groschel K. Clinic intravenous thrombolysis for stroke recurring within 3 months. Aktuelle Neurologie. 2016:43:E25.

48. Karlinski M, Kobayashi A, Czlonkowska A, Mikulik R, Vaclavik D, Brozman M, Gdovinova Z, Svigelj V, Csiba L, Fekete K, et al. Intravenous thrombolysis for stroke recurring within 3 months from the previous event. Stroke. 2015;46: 3184-9.

49. Kral M, Skoloudik D, Opavsky R, Sanak D, Vlachova I, Herzig R, Kanovsky P. Systemic thrombolysis and sonothrombolysis in management of ischemic stroke occurred during an attack of migraine: a case report. Eur J Neurol. 2008;15:257.

50. Asaithambi G, Hassan A, Grigoryan M, Chaudhry S, Qureshi A. Obese patients receiving intravenous thrombolysis in acute ischemic stroke have lower rates of Intracerebral hemorrhage and mortality. Neurology. 2012;78: $123-30$.

51. Seet RCS, Zhang Y, Wijdicks EFM, Rabinstein AA. Thrombolysis outcomes among obese and overweight stroke patients: an age-and National Institutes of Health stroke scale-matched comparison. J Stroke Cerebrovasc Dis. 2014;23:1-6.

52. Kunz A, Ebinger M, Geisler F, Rozanski M, Waldschmidt C, Weber JE, Wendt M, Winter B, Zieschang K, Fiebach JB, et al. Functional outcomes of prehospital thrombolysis in a mobile stroke treatment unit compared with conventional care: an observational registry study. Lancet Neurol. 2016;15: 1035-43.

53. Chroinin DN, Callaly EL, Duggan J, Merwick A, Hannon N, Sheehan O, Marnane M, Horgan G, Williams EB, Harris D, et al. Association between acute statin therapy, survival, and improved functional outcome after ischemic stroke the North Dublin population stroke study. Stroke. 2011;42: 1021-9.

54. Hong KS, Lee JS. Statins in acute ischemic stroke: a systematic review. J Stroke. 2015;17:282-301.

55. Matsuo R, Kamouchi M, Fukuda H, Hata J, Wakisaka Y, Kuroda J, Ago T, Kitazono T. Investigators FSR: Intravenous thrombolysis with recombinant tissue plasminogen activator for ischemic stroke patients over 80 years old: the Fukuoka stroke registry. PLoS One 2014; 9:142-152.

56. Poupore N, Strat D, Mackey T, Nathaniel IT. The association between an antecedent of transient ischemic attack prior to onset of stroke and functional ambulatory outcome. Clin Appl Thromb Hemost. 2020;26:1-11.

57. Tate M, Shugart R, Moraney MR, Brechtel L, Blum B, Nathaniel IT. Gender and functional outcomes in pre-stroke depressive patients treated with thrombolytic therapy. Future Neurol. 2020;5:67-71.

58. Longstreth WT, Katz R, Tirschwell DL, Cushman M, Psaty BM. Intravenous tissue plasminogen activator and stroke in the elderly. Am J Emerg Med. 2010;28:359-63.
59. Tanne D, Kasner SE, Demchuk AM, Koren-Morag N, Hanson S, Grond M, Levine SR, Multicenter Rt PAASS. Markers of increased risk of intracerebral hemorrhage after intravenous recombinant tissue plasminogen activator therapy for acute ischemic stroke in clinical practice the multicenter rt-PA acute stroke survey. Circulation. 2002;105:1679-85.

60. Saver JL. Hemorrhage after thrombolytic therapy for stroke - the clinically relevant number needed to harm. Stroke. 2007:38:2279-83.

61. Berrouschot J, Rother J, Glahn J, Kucinski T, Fiehler J, Thomalla G. Outcome and severe hemorrhagic complications of intravenous thrombolysis with tissue plasminogen activator in very old $(>=80$ years) stroke patients. Stroke. 2005;36:2421-5.

62. Moraney R, Poupore N, Shugart R, Tate M, Snell A, Brown K, Nathaniel IT. Thrombolytic therapy in ischemic stroke patients with pre-stroke depression in the telestroke vs non-telestroke. J Cerebrovasc Dis. 2020;5:45-52.

63. Scalise M, Brechtel L, Conn Z, Bailes B, Gainey J, Nathaniel IT. Predicting ambulatory recovery in acute ischemic stroke patients with thrombolytic therapy. Future Neurol. 2020;6:87-96.

64. Paciaroni M, Agnelli G, Becattini C, Investigators RAFS. Early recurrence and cerebral bleeding in patients with acute ischemic stroke and atrial fibrillation: effect of anticoagulation and its timing. the RAF study. Eur Heart J. 2015;36:986

65. Liakopoulos OJ, Choi YH, Kuhn EW, Wittwer T, Borys M, Madershahian N, Wassmer G, Wahlers T. Statins for prevention of atrial fibrillation after cardiac surgery: a systematic literature review. J Thorac Cardiovasc Surg. 2009;138: 678-U199.

66. Reilly SN, Jayaram R, Nahar K, Antoniades C, Verheule S, Channon KM, Alp NJ, Schotten $U$, Casadei B. Atrial sources of reactive oxygen species vary with the duration and substrate of atrial fibrillation implications for the antiarrhythmic effect of statins. Circulation. 2011;124:1107-U1191.

67. Mohammad S, Nguyen H, Nguyen M, Abdel-Rasoul M, Nguyen $V$, Nguyen CD, Nguyen KT, Li L, Kitzmiller JP. Pleiotropic effects of statins: untapped potential for statin pharmacotherapy. Curr Vasc Pharmacol. 2019;17:239-61.

68. van Dongen MME, Aarnio K, Martinez-Majander N, Pirinen J, Sinisalo J, Lehto M, Kaste M, Tatlisumak T, de Leeuw FE, Putaala J. Use of statins after ischemic stroke in young adults and its association with long-term outcome. Stroke. 2019;50:3385-92.

69. Rehman T, Hassan K, Gul W. Impact of statins on outcome of patients suffering from cerebral ischemic stroke. Indo Am J Pharm Sci. 2019;6:13146-50.

70. He LY, Xu RH, Wang J, Zhang LL, Zhang LJ, Zhao W, Dong WW. Prestroke statins use reduces oxidized low density lipoprotein levels and improves clinical outcomes in patients with atrial fibrillation related acute ischemic stroke. BMC Neurol. 2019;19:56-62.

71. Montaner J, Chacon P, Krupinski J, Rubio F, Millan M, Escudero D, Hereu P, Molina C, Quintana M, Alvarez-Sabin J. Safety and efficacy of statins in the acute phase of ischemic stroke: the MISTICS trial. Stroke. 2004;35:293.

72. Flint AC, Kamel H, Navi BB, Rao VA, Faigeles BS, Conell C, Klingman JG, Sidney S, Hills NK, Sorel M, et al. Statin use during ischemic stroke hospitalization is strongly associated with improved Poststroke survival. Stroke. 2012;43:147-54

73. Whiteley WN, Slot KB, Fernandes P, Sandercock P, Wardlaw J. Risk factors for intracranial hemorrhage in acute ischemic stroke patients treated with recombinant tissue plasminogen activator a systematic review and metaanalysis of 55 studies. Stroke. 2012;43:2904-U2235.

74. Montaner J, Bustamante A, Garcia-Matas S, Martinez-Zabaleta M, Jimenez C, de la Torre J, Rubio FR, Segura T, Masjuan J, Canovas D, et al. Combination of thrombolysis and statins in acute stroke is safe results of the STARS randomized trial (stroke treatment with acute reperfusion and simvastatin). Stroke. 2016;47:2870-3.

75. Flint AC, Kamel H, Navi BB, Rao VA, Faigeles BS, Conell C, Klingman JG, Hills NK, Nguyen-Huynh M, Cullen SP, et al. Inpatient statin use predicts improved ischemic stroke discharge disposition. Neurology. 2012;78:1678-83.

\section{Publisher's Note}

Springer Nature remains neutral with regard to jurisdictional claims in published maps and institutional affiliations. 